\title{
Utilizing Participant Voice in Volunteer Training
}

\author{
Delvin Varghese \\ Action Lab, Monash \\ University \\ Melbourne, Australia \\ delvin.varghese@monash.edu
}

\author{
Jay Rainey \\ Open Lab, Newcastle \\ University \\ Newcastle upon Tyne, UK \\ j.rainey2@ncl.ac.uk
}

\author{
Kyle Montague \\ Open Lab, Newcastle \\ University \\ Newcastle upon Tyne, UK \\ kyle.montague@ncl.ac.uk
}

\author{
Tom Bartindale \\ Action Lab, Monash \\ University \\ Melbourne, Australia \\ tom.bartindale@monash.edu
}

\author{
Patrick Olivier \\ Action Lab, Monash \\ University \\ Melbourne, Australia \\ patrick.olivier@monash.edu
}

\begin{abstract}
Delivering training to volunteers is a huge challenge for nongovernmental organizations (NGOs). Traditional classroombased approaches that dominate training are problematic due to the limited participation they offer to trainees. Peer-led approaches however, have shown promise in helping NGOs utilize trainee experiences within training. Although technologies are playing an increasing role in training, their benefits are not well understood. We describe our experience of designing peer-led training for community volunteers in rural India. Working alongside an NGO involved in community regeneration and social action, we collaboratively delivered a ten-day training workshop, deploying audio technologies to engage the participants in sharing lived experiences. We draw on reflections from trainers and trainees on how utilizing participant voice can enhance training. We highlight opportunities around the usage of audio technologies for engaging with participant voice, including the ability to reclaim trainee agency within training and to work within cultural barriers.
\end{abstract}

\section{Author Keywords}

NGO; Organizational Training; Learning; HCI4D; ICTD; Audio Technologies

\section{CCS Concepts}

-Human-centered computing $\rightarrow$ Human computer interaction (HCI); User studies; •Applied computing $\rightarrow$ Collaborative learning;

\section{INTRODUCTION}

Training is a key part of the political economies of development, helping to secure funding and provide competitive ad-

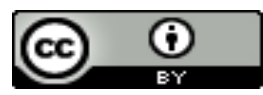

This work is licensed under a Creative Commons Attribution International 4.0 License.

CHI '20, April 25-30, 2020, Honolulu, HI, USA.

(C) 2020 Copyright is held by the owner/author(s)

ACM ISBN 978-1-4503-6708-0/20/04

http://dx.doi.org/10.1145/3313831.3376208 vantage to individuals seeking career advancement. Over the last few decades, sociocultural, technological and economic forces have forced organizations to re-examine how they train their workforce $[22,61]$. However, training of volunteers is a less understood space, despite its ubiquity in the development sector [35]. While the training of international volunteers - i.e. individuals from Western contexts who volunteer in Development contexts - has been extensively researched [2, 59], methods for training local volunteers, who are far more numerous, has received less attention.

There is an assumption that the primary contribution of local volunteers lies in their knowledge of specific contexts and challenges $[19,68]$. However, how this local knowledge might be utilized within training agendas and practices has not been investigated due to an emphasis on training practices delivered 'top down' through large organizations. As volunteers play increasingly important roles in service-delivery and intervention innovation for non-governmental organizations (NGOs) by acting as essential capacity in humanitarian crises, ensuring adequate and appropriate volunteer training is becoming a prominent challenge. To support this, it is crucial to develop methods of training that build from volunteers' contextual knowledge, past experiences of volunteering, and social connections. This contribution is often framed as participant voice or lived experience $[71,11]$, and is core to building contextually relevant peer-based training.

The inherently resource constrained nature of Development contexts, where volunteering training occurs, raises two further challenges: (i) the growing importance of gaining skills and accreditation for volunteers' professional and personal development [3]; and (ii) varying textual literacy levels among the local population [48]. These practicalities have propelled the deployment of technology targeted at supporting participants, particularly through media technologies (audio and video) [49]. The HCI community has looked extensively at the application of media technologies to engage under-served communities, enabling the sharing of community voice in domains that include: health awareness [40], cultural entertainment [42], citizen journalism [50] and translation support 
[10]. However though anecdotally observed, the role of media technologies in volunteer engagement and training remains yet to be clearly understood.

To understand the value that technology could have in enabling participant voice within training in Development contexts, we worked closely with a small NGO in rural India who train volunteers for social awareness and community development initiatives. Against the background of varied languages and textual literacy levels present among the NGO's volunteers, we piloted an audio technology to explore its impact on the training experience of local volunteers.

This paper reports on the delivery of training and shares reflections from trainers and trainees on using technology to utilize participant voice in resource-constrained local training settings. We present how this affects trainer-trainee dynamics, putting forward valuable lessons for designing such systems. While our study is not an evaluation of any particular system, it is an exploration of how media technologies can be used in a context where little prior work exists. Our findings contribute to the emerging HCI literature around the values and challenges of deploying media technologies for peer-led processes in resource-constrained settings in two ways: (i) we have shown through a real-world deployment, framed as an exploratory study, the utility of voice for the delivery of training and (ii) characterize the challenges experienced by participants from engaging in these activities.

\section{RELATED WORK}

\section{Audio Technologies as a Design Medium}

Many of the assumptions underpinning mainstream HCI research do not apply in development contexts where varying levels of media and textual literacies are present $[26,76]$. This has encouraged research into text-free and speech-based user interfaces and notably, Interactive Voice Response (IVR) systems [13, 48, 65]. Speech interfaces have supported designs across a range of contexts, including: low-literacy populations in areas such as citizen journalism [50], grievance redress [46, 53], cultural archiving [73] and leisure [60]. This is in line with broader trends around technology use in Developing contexts: countries in Asia-Pacific have an above average proportion of internet users who use voice controlled functionality on devices [36]. Uptake is highest in India - the context of our study - where $51 \%$ of internet users utilize voice controlled functionality as opposed to the worldwide average of $39 \%$ [41].

Furthermore, it is important to be sensitive to the culture, values and motivations of the local community when designing within such complex contexts [20]. As such, audio (i.e. verbal communication) has shown to be a useful medium in which to design for these communities $[7,75]$. The affordances of audio technologies accommodate a diverse population of users and tasks that they carry out $[52,72]$. In addition, diverse approaches exist to configure community learning and feedback processes within the HCI literature around audio technologies $[10,40,73,54,5]$.

\section{Utilizing Participant Contributions}

We situate this work within the stream of HCI research that views learning as a social process and as a role that emphasizes growth in their skills and capabilities characterized by participation, commitment, belonging and identity [44]. There has been increasing awareness of the potential of individual and community voice within HCI work in organizational processes $[17,58]$. We refer not only to the work of sub-disciplines such as Participatory Design and Co-Design but a wider consensus that bringing voices to a conversation entails more than "just add users and stir" [51].

There have been numerous attempts to harness the potential of participant voice to support learning and feedback mechanisms $[40,17]$. To facilitate peer-learning and social connectedness within a rural community, Patel et al. [54] designed a audio-based forum for members to engage and learn from one another. Others have looked at designing systems with more sustained engagement, utilizing participant voice to support Development workers involved in knowledge dissemination. Community Health Workers (CHWs) support remote populations who do not have easy access to healthcare providers. Kazakos et al. [40] designed an interactive IVR-based system inspired by community radio practices to help these CHWs leverage the voice of the population that they serve. In this way, best practices for maternal health were shared through a peer-learning approach across a large area over which their population were spread. The process enabled health workers to conduct radio show discussions with rural participants and noted the potential for voice-based platforms to provide participants with comfort and a sense of connection with each other.

These and similar studies were aimed at participants who were geographically distributed, aiming to foster a network of information exchange. Similarly, Dow et al. [17] have looked at providing voice feedback opportunities to service users of an organization who had a range of disabilities, overcoming the limitations of traditional modes of feedback delivery. In this work, using participant voice as feedback was linked to the perceived value that the participant gained from the organization [17].

Finally, Rainey et al. $[58,5]$, explored the ways that organizations capture participant voice to aid feedback and reflection processes. Going further than the capture of audio or the facilitation of learning, a commitment to participatory sensemaking was evident, whereby the practitioners were able to conduct sense-making activities and deliver group-based training or individual feedback to stakeholders using the original audio media.

We build on the use of audio within the domain of staff and volunteer training in NGOs. Participant input, particularly using audio can help with learning and training, reducing social distance in classrooms, enhancing teaching presence and fostering a greater sense of community among students [34]. Technologies designed for the classroom encourage participation by learners [37]. Audio as a modality has another advantage: it allows stakeholders to capture experiences in-situ, as it is a natural and fundamental part of human communication, 
in contrast to written communication that requires additional literacy [45].

\section{Organizational Training and Technology}

Previous HCI research has investigated the role of organizational training within emergency and disaster settings [21, 43]. Other work has compared the effectiveness of trainer-led classroom instruction and technology-aided self instruction $[1,55$, 56]. Technology has played a key role in training innovation across a range of contexts, including: virtual reality simulations, games and e-learning. The rise of social networking platforms have altered the nature of the organizational training space [24, 61]. Although computer based [56] and online [67] instruction have shown to be effective for delivery in these contexts, it is key to "tailor their training programs more closely to the demographic" [56] to leverage the cost reduction offered by technology.

As McKeachie et al. note, "successful incorporation of technology tools depends on the extent to which they are connected to course goals, combined with effective pedagogies and designed to improve [training] rather than being used for their own sake" [47] (p. 231).

Within organizations, lectures are frequently used for knowledge transfer in formal learning contexts, especially for staff training [53]. However, while lectures are effective at presenting large quantities of information in short periods of time to large audiences, they offer limited opportunities for participation for students or trainees to become actively involved [55]. They are also ineffective when long-term knowledge retention is required [31]. To overcome these limitations in classroom contexts, practitioners have developed innovative approaches to increase participation (aided by technologies) e.g. flipped classrooms [30] and \#CClasses (Connecting classes) [77]. This is because training methods aim to target the affective domain, i.e. learning that "involves changes in interests, attitudes, and values" [9, p. 9]. Training practitioners have noted the benefit of group discussions, role-playing, and brainstorming as techniques to encourage learning in this domain.

Group discussions, in particular, serve multiple purposes, including intellectual, emotional and social learning [55]. They help participants become aware of the complexities of issues, encouraging an "affective quality that is key to the building of self-confidence and a sense of belonging" [55]. They also build a sense of cohesion and trust that allows for the diffusion of new ideas and attitudes. For training to be successful, the trainee needs to support trainees in learning new skills. To achieve this, practical training methods that go beyond the typical classroom learning environment are required, especially methods that are more effective for the changing realities of work in the modern era [24] than traditional lecture-based approaches [1].

\section{CONTEXT}

BE Foundation (BEF) is an NGO based in south east India that provides interpersonal skills training to community youth volunteers. BEF regularly conducts awareness raising campaigns within schools and colleges across the district to recruit and train community members. The organization has three trainers that have a combined 18 years of training experience. Their existing approach to volunteer training is a co-located workshop, consisting of classroom-based sessions and is attended by participants from across the region.

The organization had already identified active trainee engagement as a key capacity to strengthen (cf. [53]), and wanted to investigate how existing technology could create engaging trainee experiences. In a context that could be characterized as an oral culture [64], the trainers understandably wanted to use a speech-based process due to their familiarity with speech interfaces and fluency with using calls and WhatsApp voice notes. Drawing from existing training practices, discussions were held about speech-based approaches that could be incorporated into the classroom context. However, existing approaches within HCI for Development research (HCI4D), such as IVR and Community Radio, were not appropriate due to the organization's training model and concerns about software maintenance and sustainability.

Through discussions with organizational stakeholders, we identified three key priorities to support digitally-enhanced training: (i) limiting the financial and resource overhead of introducing technology to the process; (ii) supporting the creation of artifacts from training events that could be reused and re-purposed in future events or distributed online through their social media channels (to target volunteers who were not present); and (iii) building on their existing approach of interactive classroom-based activities, increasing trainee participation and peer-learning. To deliver on these priorities, BEF saw the advantages of audio technologies to facilitate the process.

Additionally, there was a lack of desire to use video-based approaches due to the trainers having limited experience facilitating video-based activities (and reservations about learning new skills, which they would need to effectively facilitate this). Consequently, the organization selected Gabber, an open-source, mobile application designed for the capture and analysis of semi-structured audio conversations [58]. This system had been successfully deployed in similar NGO settings. Gabber uses textual topics to structure conversations, with which participants are prompted in the mobile application when recording conversations. These recordings are uploaded to a website where participants in the conversation can view a visualization of the recording which is tagged and color-coded with the associated topics. The use of Gabber would ensure no financial costs and low resource overhead (i.e. learning how to use the system), and enables the creation of audio artifacts with related textual topics that can be shared with a wider group.

\section{STUDY DESIGN}

This section is divided into two phases that describe: a ten-day training event where Gabber was used to augment BEF's training practices, and post-training interviews with both trainers and trainees. Across these, our research sought to explore two design questions: (i) how can audio technologies be leveraged to overcome the situational and contextual challenges of local volunteer training; and (ii) how can the use of audio technologies support sustainable and flexible modes of training driven 
by peer-led participant voice. Full ethical approval was received from our Faculty Research Ethics Committee (assessed as a "high risk" project), and written consent was given by all participants from the outset.

\section{Training Event}

The organization conducts an annual ten-day workshop (eighthour days) to deliver a compressed training package to around 30 community youth volunteers from across a wide geographical region. Consequently, participants have a broad range of native languages (e.g. Tamil, Malayalam, and Telugu), however, English is used by the organization as their communication language. A workshop-based format is used to provide training on soft-skills development in the following four areas: (i) enabling volunteers to think critically about issues in their local community; (ii) providing approaches used in International Development and recommendations provided by NGOs such as United Nations etc., reflecting on how these can be used to address challenges in their communities; (iii) building interpersonal skills such as communication, conflict resolution and goal setting; and (iv) providing leadership training to reflect on different styles of leadership and identify their preferred styles, highlighting teamwork and problem solving.

Gabber was configured to augment existing training workshops across three activities: (i) trainees recording conversations around topics set by the trainee (experience capture), (ii) the trainer reflecting on and curating snippets for reuse (trainer reflections), and (iii) the trainer using the curated data to deliver training and inform discussion (around reflections). We sought to minimise social desirability bias [14] by reiterating to participants the exploratory nature of the work, and that we expected processes to not work (and we welcomed critical feedback). Additionally, through triangulation of interview and observation data where possible, we further aimed to reduce this bias.

\section{Participants}

Two of the trainers were experienced in facilitating social action and participatory youth empowerment initiatives, while the third trainer was a new member of the training team. In total, there were 28 trainees (14 male, 14 female) and three trainers (all male).

The majority of the volunteers were youth from rural backgrounds, who were either in college or recent school leavers from a low socio-economic background. They had each traveled three hours or more to attend the workshop. The youth had varying levels of volunteering experience. To foster peerbased learning and a sense of teamwork, participants were allocated into one of six groups. Each group proposed a group name and appointed a facilitator from within their team to mange group conversations.

The lead researcher observed the use of Gabber and interviewed both trainers and trainees throughout the week to gain an understanding of the role of audio and participant voice within the training environment. The three activities were facilitated on three days of the workshop (i.e. each of the following activities was conducted three times each over the course of the training).

\section{Activity 1: Experience Capture}

Text-based conversation prompts were designed by the trainers and consisted of open-ended questions based on the session topic. The questions ranged from general introspection e.g. Discuss how volunteerism can help you develop leadership skills; Discuss why setting goals is important to specific soliciting responses e.g. How will you support volunteering in the next year?; What support do you need from us for volunteering in the next year?

In the initial workshop session, the trainee groups' coordinators were given a mobile phone with the Gabber application pre-installed. During each instance of the activity, the coordinators led their groups to a different location for 20 minutes, and held the phone in their hands to capture audio recordings in response to each conversation prompt. Participants were encouraged to have 'informal conversations' with no expectations on arriving at a 'correct answer' and yet, many chose to rehearse and record multiple recordings. We saw no regimented order in which recordings were conducted. Focus was placed on group reflections and the exploration of ideas. The aim of these sessions were to "allow participants to discuss issues to achieve understanding and consensus after consideration of the viewpoints and ideas of others" [55]. Participants agreed that their recordings could be re-used in the subsequent reflection and discussion activities, which the trainers thought would motivate and incentivise the participants to record informal conversations that they could share with other participants [73].

\section{Activity 2: Trainer Reflections on Experience}

After Experience Capture sessions were conducted, the audio recordings were retrieved from Gabber, and were listened to and reflected upon by the trainer using a laptop during the workshop review sessions (at the end of each day). The trainers listened to the clips recorded that day, which took between 10 to 20 minutes. Practitioners have previously identified the need for learning processes within organizations that promote the sharing of knowledge within members of an organization, and spaces to reflect on their views and actions [63]. These processes have spaces for reflection built in, which have helped employees share their implicit expertise through explicit representation to others [18].

Trainers selected audio clips to match each of the following criteria that could be later used as discussion prompts with trainees: (i) examples of recordings that demonstrated strong critical reflection on the conversation prompts, to praise and motivate the participants; (ii) examples where no teamwork or engagement with prompt questions was evidenced, to help groups improve their responses; and (iii) examples that contained creative responses which helped the trainer gain new insights.

\section{Activity 3: Discussion around Reflections}

Based on the highlighted recordings, a Reflection activity (4560 minute session) was conducted with trainees on the following day. In this activity, the audio clips selected by the trainers would be played to everyone in the room, and open-ended questions would be posed to the participants to support critical reflection on the experiences of participants around each 
topic. Participants were asked to either discuss in their groups or to create a paper artifact to represent their reflections (for example, a mind-map that shows how certain concepts discussed are enacted in their individual volunteering journeys). For instance, in the first session, an audio clip submitted by participants in one of the groups was chosen, which discussed a need for more training programs that highlight opportunities to work with other countries and organizations. This clip was selected for reflection by the trainer due to this group talking about working with other organizations. A paper artifact was then created around this audio, which involved asking the trainees to draw a chart of other organizations that the volunteers could collaborate with. The aim of this activity was to help them identify avenues for support in their immediate locale.

\section{Data Collection \& Analysis}

A mixed methods approach was taken to data collection and analysis. Qualitative data in the form of semi-structured interviews were conducted and audio recorded at the end of the workshop (in English - as the lead author, despite being a native Indian, was not a member of the local community), to evaluate trainee and trainer experiences of utilizing participant voice in the delivery of training during the workshop. Of the 28 trainees, 19 agreed to take part in interviews with the researcher (others were unable due to travel constraints), along with all 3 trainers, whom we abbreviated as P1-19 and T1-3 respectively. Interviews began by discussing the trainees backgrounds and volunteering experiences. We then moved on to discuss the following three areas: (i) trainee reflections on participation (group work) within the workshop (ii) their views on audio usage and audio technologies; and (iii) positive and negative experiences of training using these approaches compared to other approaches they'd encountered.

In addition, extensive field notes were taken by the first author and participant observation principles were followed to capture the behavior of trainers and trainees throughout the training workshop sessions. This was augmented with design outputs from the workshop activities and voice recordings by trainees which were also analyzed. The voice recordings (total of 40.5 minutes) and interview recordings were transcribed verbatim by the lead author and inductively thematically analyzed with an emphasis on understanding our initial design questions [8]. A code book was derived and iteratively refined by independent coding on a selected sample of two transcripts. Three such iterations were conducted to create a preliminary code book. The transcription of voice recordings was done together with the trainers at the end of the workshop, as some recordings were in local languages or dialects. These were then reviewed against the discussion prompts given to participants.

\section{FINDINGS}

\section{Summary of Captured Media}

Across the three experience capture sessions, participants produced a total of 50 recordings (Mean $=49.41 s, S D=60.42 s$ ). In the first session, participants captured a total of 21 audio clips ( $42 \%$ of total). However, as this was their initial session, the captured discussions were short and not conversation-oriented (Mean $=19.67 s, S D=19.92 s$ ). The second group was an exception and recorded the longer discussions across groups (Mean= $55.70 \mathrm{~s}, S D=15.57 \mathrm{~s})$. The next longest group recording being approximately half as long. The range of contribution length varied from the second group (Mean length of audio $=137.73 \mathrm{~s}$, $S D=97.79 \mathrm{~s}$ ), to the first group (Mean length of audio $=12 \mathrm{~s}$, $S D=7.81 \mathrm{~s}$ ). We did not find any instances of inappropriate or ethically challenging clips.

\section{Post-Training Interviews}

Our findings are framed by within main themes: (i) teamwork and Competition (analyzing how the trainees interacted with peers both inside and outside their groups), (ii) navigating emotions around voice (showing how the trainees exhibited a variety of emotional responses to the use of voice and what they signify), (iii) molding their own empowerment (how voice enables gaining of confidence in the face of social and cultural barriers ) and (iv) gaining an inner and outer voice (trainers and trainees discussing the role of voice technologies in improving their skill-set and reach).

\section{Teamwork Tensions: A Serious Task?}

Trainers had instructed the trainees that recordings were being conducted to increase the interactivity of workshops and enable the reuse of training material. Throughout the workshop sessions, trainers also reminded the trainees that there was no obligation to record a 'correct' answer and that all responses were welcome. Despite this, some trainees interpreted the task of recording audio clips and sharing experiences in their groups as a serious task, which needed to be conducted with diligence. As one trainee said, "we have to know it's very serious... we have to give valuable points that give much awareness to others" [P8].

Another participant similarly emphasized the severity of the task, and shared reasons why they took the sessions seriously: "it is not for entertainment, it is for education, to develop the people's knowledge" [P21]. Some participants also put high expectations on the quality of their output. However, this viewpoint was not shared by all trainees, for example, one trainee noted that they didn't take the tasks as seriously as they ought to have: "I was roaming around, speaking with others... and I [engaged] less, to be frank!" [P6].

The 'serious' trainees not only expected high quality responses from themselves, but also from their peers. P17 expressed grief about their group's poor performance and attributed it to a lack of seriousness: "some of them in [my] group haven't put the effort in, that was the failure of our team" [P17]. The expectations that some group members had about the appropriate levels of participation required of each member, caused conflict within the group, as the 'serious' trainees felt let down by their team members' reticence about participation.

They perceived that the team should have performed the serious tasks of discussing, rehearsing and concentrating on delivering team output. In contrast, the 'non-serious' trainees moved around the event space, talking to various people and intermittently taking part in their group's activities. For the trainers, this was not necessarily disruptive behavior, as they 
encouraged the trainees to have informal discussions with each other about the prompts. Additionally, the free admission on part of the 'non-serious' trainee also shows their embrace of the informal aspect of the process.

Divergent views were often shared by participants in a group for the same questions. Some participants found this an uncomfortable experience, as for many of them, coming from very rural contexts, this was the first time that they had been exposed to the diverse views and experiences of people from different backgrounds. The trainers saw this as positive, with one trainer highlighting that this was evidence that the views they had expressed were genuine and not rehearsed:

"[they] may have a different opinion because they have taken a chance... it's like a reality show so they express their real views on the spot" [T1].

Using speech introduced a level of spontaneity to the dynamics of interactions between trainees. The practice of rehearsing speech contributions mentioned above is not in this context incongruous with our characterization of spontaneity: it was often part of an agreed-upon workflow within the group to have free-flowing conversation followed by a rehearsed summarization of the essence of their discussions. Participants were also able to distinguish between viewpoints that were entirely different, and ideas that seemed different but just needed restructuring before sharing:

"Sometimes we have the same thought but expressed in different ways. We have to combine them and then it's given in a proper manner" [P8].

The trainers noted the unanticipated moments that emerge through the use of technologies that capture informal conversations. In comparing it to a reality show, where the unscripted nature changes the dynamics of participation between stakeholders, the use of informal, unstructured conversations in the training context could be trusted to contain 'genuine' views.

\section{Self-Improvement through Peer Validation}

Participants also commented on the benefits and drawbacks of using a technology-mediated training compared to their expectations of a traditional training delivery model. They described that it made them confront their fears (of public speaking and sharing their views openly) and equally that this was a thrilling opportunity. One trainer commented that,

"[Technology] It is giving a chance to every participant to work on their fear and everybody felt very proud to hear their voices in front of other people" [T3].

The trainees repeatedly expressed positive emotions when recalling how their group's contributions were chosen and shared in the review sessions. This was noticed when observing the participants as well, as various groups would whisper among themselves trying to identify which group's contribution was currently being listened to. Once they identified the voice, they would all look in the direction of the person whose voice was being played, giving affirming looks and actions (such as a thumbs up gesture).
"If my voice is there, all of them are looking at me. I feel like 'oh my god!' ((laughs)) They're all looking at me! It was such a nice experience for me" [P18].

Initially what seems like embarrassment is revealed to be a mixture of embarrassment and pride. Here we see again the trainees reflecting on the attention they received as their voice was played back by the trainer, and it gave them a sense of recognition and achievement. They had performed in front of their colleagues and public acknowledgment was the reward for their participation. One trainee suggested that having no option but to listen to other people's contributions would help give confidence to those who perhaps have doubts about what they have shared:

"[Initially] I feared whether [my contribution] is right or wrong. But the second one onwards, everyone has to listen to our voice... I'm so happy because every group has to listen to every single word" [P9].

Participants felt that the technology facilitated a safe space to compete with each other. This came through in many of their reflections where they expressed a determination to want to be better than the other groups and the sense of achievement they felt when their voice was recognized by other groups:

"they spoke for a greater duration, compared to us, we spoke for less. We wanted to do better than them, that's how I thought." [P6].

However, there was still a supportive environment, and participants happily encouraged each other when their clips were inspiring them in a certain direction. There was no sense of conflict for them in having competitive feelings and at the same time fostering a supportive environment:

"People are supporting us and lifting us to the top level, we felt like we had to perform well. And we have to share more information they are getting energy through it" [P10].

The trainees were driven to contribute and be recognized by the trainers and their peers. As each trainee belonged to a group, they developed a sense of group identity over the course of the training. Individual recognition of peers also contributed to the group's status, which in turn helped elevate the person's status both within their immediate group and the wider group of workshop participants.

A supportive yet competitive environment was pervasive in the workshop activities. Participants described how they experienced a range of emotions when their group's voice or the voice of another group was utilized in the training sessions e.g. feelings of nervousness and a desire to be better than other groups. While others expressed either frustration with themselves or praise for another group when the other group had mentioned points in discussion which they had forgotten to:

"while others voice was played, I have felt happy for them, that they have done their best and their ideas was new and something different. And I thought, 'OK, we have to do more than them. In our next time, we have 
to play the best possible role and we have to be placed there [at the top].' That is also another motivation for me" [P1].

\section{Molding their own Empowerment}

Local social constructs around gender roles impacted on group dynamics and participant behavior within the workshop activities. One participant summarized the issue as:

“...in Tamil Nadu and Indian culture, women are not allowed to participate in volunteerism and even in my home also, they do not allow me to come home late. This is a [drawback] for the women who want to achieve their goals or if they want to improve their community" [P8]

The participants deliberated on the obstacles they have to overcome to take part in volunteerism and training, particularly obstacles from their families and immediate society. Their desire to give back to the community is not appreciated. Within the workshop context, the introduction of audio as a resource had an impact on how participants of different genders interacted with each other in the workshop, "there was no difference, there was no gender bias, and all the participants, boys and girls, [were participating] together" [T1]. Many participants expressed the pride and affirmation they felt from the warm reception from their fellow trainees when sharing their experiences. One trainer commented on how technology helped participants face some of their fears, for example, fears related to public speaking:

"Some of the participants, like girls, they are very much afraid. Because they were thinking 'how can I [possibly] speak? Because this is a new experience for me'. Fear is a challenge some groups have faced. So even though the challenge is there, the coordinator helped and motivated the participants to overcome the fear" [T3].

Trainees (particularly female trainees) initially perceived the configuration of the training and the higher participation levels required as a challenge, and the trainers picked up on this. However, with the help of their peers and the prompting of the coordinator in the group, they were able to gain confidence in making contributions. Another trainer shared how they saw the impact on two trainees who were previously known to the trainer:

"When I [first met her], she was not able to speak a single word and she felt shy. But these ten days she spoke a lot... through the voice recording she has shared many things. And [trainee name], I can see so many changes in her. In another volunteering camp I ran, she wouldn't speak at all. In the time I've known her, she has not spoken like this" [T2].

The use of audio helped participants overcome some of their fears and gave them a sense of achievement when their contributions were publicly highlighted. They felt encouraged and affirmed when their voice was listened to by other people. In this instance, the trainer attributed this particularly to the use of audio technologies, as they had previously worked with this trainee in other training sessions where audio technologies were not used. Using an audio-based approach in the work- shop reduced some barriers for participation for many trainees. T3 commented elsewhere that:

" It made me very happy to hear their voice played So, if this [audio technology] is not there, she wouldn't be able to share her views in front of everybody" [T3].

Another trainer contrasted the methods that they typically used, which focused on theoretical aspects of volunteerism and were done through Powerpoint presentations. Utilizing participant voice, according to this trainer, had the advantage that trainees "[practically] bring their volunteerism to engage in... molding themselves" [T1]. The trainer clarified that they were referring to the active role that volunteers play in sharing experiences to help in each other's training. Similarly, another trainer added that:

"Even though PowerPoint presentations, chart presentations are there, but [with those approaches] they are not able to share their views without fear, without standing in front of everybody" [T3].

The way audio technologies enabled new levels of participation during the workshop was repeatedly stressed by trainers, often framed in contrast to previous engagement methods. The capture and reuse of voice created opportunities for trainees to share their views with new-found confidence.

\section{Gaining an Inner and Outer Voice}

Participants viewed the experience sharing and capture sessions as a way to improve their professional skill-set, such as their communication and language skills. One participant shared: "in many ways [this technology] helps improve your language skills, you can interact with many people without any fear, you can build your self-confidence" [P8]. In their initial attempts, trainees had taken part in discussions with no clear flow, but as their confidence in using audio in their groups increased, they felt more comfortable having longer conversations: "we didn't have any ideas in the first and second tasks... it was much easier to do the third task" [P18].

A few who were shy found it helpful to write down their points on paper and let other members of their group speak out, for example, two trainees were happy to match their strengths together in this way to create a shared response. A trainee who mentioned some points for a certain topic was not confident in having her voice recorded, so she gave her points to a group member who was happy to receive these points and have her voice recorded:

"She spoke in her voice, but used my writing because my voice is not good... she is [thanking me] and all. And everyone got to listen to my voice. (Laughs)" [P9].

Interestingly, this trainee saw her points being spoken by another person as equivalent to her voice being heard. The trainee saw their voice as being synonymous with their views or their opinions, regardless of who vocalized it, thus distinguishing between inner voice and spoken voice.

Trainees also mentioned how using technologies after the workshop would be a good way to reach more people with the organization's activities. In particular, supporting authorship 
and attribution, and how the workshop material could reach new people, for example, "to run youth panels with members from one place to another" [P8]. The modes that they envisaged ranged from the sharing of resources to the sharing of awareness:

“...'trainers/volunteers can get to know...'how they can train the village people or the community [beneficiaries]. So, this method can help us to communicate with other after this [workshop]" [P15].

For the trainees, this stemmed from the connection they felt between their voice (enabled by Gabber) and the potential for the community members they work with to be impacted: "what we spoke in our group...because of our voice the community members [beneficiaries] can also overcome their hurdles" [P18]. The lead trainer reflected on many opportunities that voice technologies afforded their organization in facilitating the sharing of information between networks of institutions: "[We can] start using the application for school-to-school contacts or teacher-to-teacher contacts..." [T1]. On the other hand, for the trainees, sharing their voices and volunteering experiences with their friends and fellow volunteers was the key motivation:

"I can explain about this to my friends also, they are also in same field as social work... [and] use this app to do their own field work" [P24].

Some trainees relished the notion of their contributions being reused in future training events and to learn from contributions in other training events: "in future training period... we can show voice records of previous years of students... to learn and get more ideas from others' use" [P21]. Perhaps surprisingly, the trainees expressed no ethical concerns with how their voice would be reused in the future, and were interested to know that their voice would find an audience beyond the immediate context in which they had shared their views.

\section{DISCUSSION}

Our findings demonstrate the opportunities and challenges of using audio technologies in the delivery of volunteer training. However, this work also has implications for the design and development of systems used in organizational processes beyond formal training mechanisms. The disruptive potential of digital technologies for organizations is discussed below and focuses on the following themes: (i) transforming organizational training delivery, (ii) addressing societal issues within technology-enabled processes, (iii) configuring modes of participation in training; and (iv) helping participants reclaim agency and a sense of authorship.

\section{Transforming Organizational Training Delivery}

Previous work has shown the potential benefits of synchronous media technologies to support communities of practice and broker the localized sharing of experiences [40]. The affordances and convenience of audio technologies [50] are evident in participants' reflections on its use as a medium both inside and outside the training workshop context. Our participants saw audio as having an impact on their productivity by allowing them to track, systematically record, and reuse audio recordings that were created as part of the training workshop. It allows for the reuse of training media outputs generated through audio technologies from a previous workshop in the training of new volunteers. We can be confident in attributing the impacts to the use of audio technologies as the organization has delivered face-to-face training as standard and this was the first time audio recording was piloted.

Additionally, bringing externally captured audio into workshops has the potential to lower the bar to active workshop participation by allowing participants the opportunity to engage with other trainees who may not be co-located in the training location. In this regard, audio recording and reuse in training sessions (as opposed to taking notes and re-presenting insights orally) was considered highly desirable. By utilizing a variety of techniques suggested within the training literature (such as group discussions and the use of audio), this work explored how trainers could configure richer forms of trainee participation. There is more to a training workshop than the training: the shared space encourages social interactions that occur before, after, and during the training [4]. These play an important role in determining the experiences of trainees. By using technology to guide informal conversations as a training strategy, the social interactions that ensue can be built into the training activities.

The use of audio technologies to facilitate comparative selfevaluation and even promote competition (or the positive and negative aspects of these), was not a design consideration we anticipated in designing our workshop activities. The participant responses in many cases arose from a desire for continuous improvement. Yet, the public nature of the attribution of the snippets of recorded voice used in the activities caused participants to critically reflect on their own contributions in light of the contributions of others.

This stood in sharp contrast to activities that facilitate faceto-face interactions rather than recorded interactions where participants were less forthcoming. In this way, audio technologies reduced the 'pressure to perform' but were seen to facilitate the process of improving performance. When audio recordings of a particular group were played in the session, others would scan the room to find out whose voice it was and smile approvingly when they recognized the participant's voice. As a result, contributions from peers were valued and encouraged.

Additionally, participants' daily experiences of living and volunteering in rural environments is quite different to the workshop context. The traditional organizational boundaries around what constitutes 'the field' and 'workshop settings' are broken down when the sharing of trainee experiences (from the field, undoubtedly) is encouraged and their voices are acknowledged, creating safe spaces for sharing their voice.

The opportunities afforded by audio technologies to support rural volunteers (many traveled considerable distances to attend training), who are otherwise not able to access regular training, were therefore foremost in their reflections. Trainees not only saw the value of audio as a training mechanism for themselves, they also envisioned audio technologies being key to engaging 
their peers in their home villages. This highlights opportunities for $\mathrm{HCI}$ researchers to leverage local volunteer knowledge and connections in engaging rural and remote communities, without increasing the burden on organizations already stretched by working with populations over large areas [23].

While this work was conducted over the course of a single workshop, the space calls for the design of processes that support longer term, light-touch processes that organizations can use to encourage their volunteers in facilitating community activities in rural locations. Examples of this could include training volunteers on leading social media campaigns and awareness raising about local issues in youth groups and school clubs. These are contexts where volunteers have access to existing peer networks, which can be leveraged without the organization needing to carry out in-situ training events that are characterized by top-down recruitment and high preparation time outlay.

\section{Social Positioning and Cultural Barriers}

The positioning of our participants within the larger community of volunteers and other members of society was apparent in their reflections on how their voices were perceived. Many of the female participants were acutely aware of gender disparities in how volunteering is performed, and were interested in how audio technologies could help them address barriers to participation in volunteerism [16]. In relation to both issues of gender, volunteer confidence, and self-improvement, we cannot claim that audio technologies are a quick fix for barriers that have deep social and cultural roots.

However, taking into account some of the comments of the participants, more work should be done to explore how technologies can be used to support communities in working around societal constraints of volunteering. Previous work has explored documentation of community experiences around advocacy for change of current societal practices [70]. It could be argued that one has to design within the constraints and barriers in order to subvert them, rather than opposing them [69]. Furthermore, there was much interest in using audio technologies not just in training, but in everyday work practices as the potential to address societal issues was explored.

Prior work has looked at how young adults in resourceconstrained settings have used technologies to explore sociopolitical issues considered taboo, for example, exclusion from STEM education, social norms that favor men, limited free time and financial and institutional constraints [25, 28]. We echo the familiar words of Silva et al. that we need to be aware of 'participation gap' just as much as 'access gap' [66], i.e. the trainees may have access to technologies and platforms such as volunteering and community mobilization initiatives, but there are still barriers around how they can use them and how they can be provided with mentorship and skill-building activities.

The successful implementation of new systems can have unintended consequences for individuals and organizations, which might even be contrary to initially set goals [57]. Enabling marginalized participants to share their voice openly and without inhibition through the use of technologies can have neg- ative repercussions on the individuals, not just in terms of their participation in civil society, but in society at large. We encourage researchers working in this domain to further investigate ways audio technologies can be appropriately integrated within organizational contexts where there can be dangers associated with participation. Within our context, we see value for ethical safeguards that allow participants to take control of how their voice is used: not just at the point of sharing, but for opportunities to retract or redact their voice. This might seem counter-productive in light of our discussions around gaining confidence and enabling empowerment. However, broader conversations within Development studies describe the tyranny of participation and the disempowering effects of participation (and over-participation) [32]. We advocate for processes that give those who participate the right to limit or alter their participation.

One way to mitigate the ethical challenges associated with using media technologies would be to consider dynamic consent $[6,39]$, where the trainee has more control of their contributions beyond the initial consent given prior to participating. This is particularly crucial in the context of content reuse, where a trainee might feel that their previous contribution is no longer representative of their views or perhaps they no longer want their views on a particular topic available to peers or other members of the organization [5]. Since the conversations were designed to be informal, the trainee might share something critical of the organization that they regret afterwards. The design of technology in such contexts must take into account content moderation and retrospective management of consent.

\section{Configuring Participation within Training Approaches}

While the use of audio has a number of benefits within a training context, there are challenges that still need to be addressed. A drawback of methods that utilize audio technologies is that the training content might not be standardized from one training event to another as new content is generated by trainees in each event. In addition, variations in quality will be introduced by the quality of trainee contributions and the facilitators' experience and skill-set [27]. Thus, what is perceived as a strength of such participatory approaches (i.e. better representing the individual, localized experiences of trainees), can also be problematic for the trainers who are limited by the conversations in that particular training event. One way to counter this is through media re-use: playing back contributions of trainees from previous training sessions. The trainer can thus coach the trainees to share their experiences and contribute by helping them see examples of good contributions from past workshops.

There is a danger that using such participatory approaches will increase the burden on NGO staff and trainers. Traditional methods for training delivery, such as lecture-based content, require less effort to deliver once prepared [55] and enable the trainer to maintain more consistency across sessions, which the use of voice technologies that utilize trainee voice make it harder to do. Trainers have to spend extra time at the end of each trainee contribution session sifting through contributions and selecting recordings. However, in our experience, trainers often review their sessions at the end of each day to see what went well and what could be improved for the following 
session. By utilizing voice recordings in their daily reviewing process, trainers can then review the day's training activities more easily rather than relying on just notes or their memory.

Like any other participatory approach, the trainer needs to ensure that specific individuals in each group do not dominate conversations at the expense of others. Previous HCI literature has suggested a number of concerns with participatory approaches for this very reason [74]. The trainer also needs to manage the expectations of those who contribute in the sessions and participants whose contributions are not utilized any further. Similarly, the trainer needs to look out for how other trainees respond to contributions. A badly received contribution could be reciprocated with negative comments or gestures by other trainees, and thus demotivate or negatively affect the trainee/group who shared the comment, affecting participation for the remaining duration of the workshop and afterwards.

\section{Reclaiming Trainee Agency and Sense of Authorship} Self-efficacy has a role as a "potent mediator of students" learning and motivation... playing an essential role in their motivation to achieve" [78]. A recurrent theme for our participants was the high motivation and self-efficacy found among them. Existing HCI research shows that "self-efficacy leads to better learning" [62]. While HCI research has explored the role of self-efficacy in contexts of community health workers [15], entrepreneurs [29] and makerspaces [33], it has received little attention in the context of training in general, and volunteer training in particular.

An observation we made was how the trainees viewed the authorship of their contributions. While they were excited by the possibility of their voice being instrumental in the training and education of others, no one mentioned any concerns about attribution or wanting to know when or how their voice was being used. No one expressed concerns about privacy or their talk points being misunderstood when removed from the immediate context of the workshop. This might be because their audio recordings hadn't yet been used outside the training context, and the potential re-use was still an imagined scenario. Further work may reveal actual trainee views on their voice being broadcast in contexts outside the training environment. Furthermore, when reflecting on their own training experience, trainees were able to come to terms with their own training development through reflections on the feedback they received in the Experience Recap sessions.

Participants felt proud imagining the possibility that their experiences would be listened to by people 'around the world' This is again related to their self-efficacy, as they believed that their opinions and discourse were valuable and worth listening to. This agency, i.e. a high confidence in their training and a sense of expertise and ownership about opinions that they had shared, shows that audio technologies might be particularly suited for participants with high self-efficacy. This is similar to previous work in HCI where participants exhibiting high self-efficacy were chosen to take part in a new learning approach, resulting in positive learning outcomes [12].

Furthermore, it also affected the trainer-trainee dynamic in the workshop context. In the workshop sessions where voice technologies were used, trainees began to realize that their experiences and opinions on training topics mattered. They began to be more expressive about their viewpoint, bringing analogies and personal anecdotes into their audio recordings to reinforce points. This was also confirmed by how some participants expressed a sense of importance about what they had shared, feeling the need to share something of worth rather than simply expressing an opinion, as they knew that their recording would be listened to and inspire others.

Properly managed, using voice based technologies can give participants a greater sense of agency and power in their training experience, particularly those with high self-efficacy. Rather than perceiving themselves as passive recipients of 'received knowledge', they are encouraged to see themselves as co-producers of knowledge. While this may blur the trainertrainee divide, causing trainers in particular to rethink what it means to run training events, our research has shown that participants rose to the challenge, producing contributions and using the experience capture method, demonstrating their competence and confidence in sharing their voice to train each other.

\section{CONCLUSIONS}

This exploratory study contributes to existing discourses around trainee participation in training by showing how the quality of contributions from trainees can impact the experience of training delivered in resource limited settings. We investigated how training volunteers can be structured by processes that encourage greater trainee participation through the use of participant voice; and how audio technologies can facilitate increased engagement in these contexts.

Our findings demonstrate that trainees were able to become agents in their own learning and at the same time participate in a community where sharing experiences are important for learning [38]. Furthermore, we highlight that despite social and cultural barriers faced by the trainees, the use of audio instilled a sense of ambition to address these barriers and a sense of pride felt in sharing their views knowing that their views are heard by others outside the context of that specific training event. Using audio to deliver training also has implications for the trainer-trainee dynamic, and we identified how the peer-led focus of processes enabled by audio technologies can contribute to a greater sense of empowerment.

\section{ACKNOWLEDGMENTS}

We thank the participants for generously giving their time. Many thanks to the BEF trainers and Ms. Helen Rice for their invaluable assistance in analyzing the data. This research was funded by the EPSRC Center for Doctoral Training in Digital Civics (award number EP/L016176/1) and the EPSRC Digital Economy Research Center (award number EP/M023001/1). Data from this publication is openly available under an 'Open Data Commons Open Database License'. Additional metadata are available at: http://dx.doi.org/10.25405/data.ncl.c. 4808400 . 


\section{REFERENCES}

[1] Winfred Arthur, Winston Bennett, Pamela S. Edens, and Suzanne T. Bell. 2003. Effectiveness of training in organizations: A meta-analysis of design and evaluation features. Journal of Applied Psychology 88, 2 (2003), 234-245. DOI :

http://dx.doi.org/10.1037/0021-9010.88.2.234

[2] Stephen G Atkins. 2012. Smartening-up Voluntourism: SmartAid's Expansion of the Personality-focused Performance Requirements Form (PPRF). International Journal of Tourism Research 14, 4 (2012), 369-390. DOI : http://dx.doi.org/10.1002/jtr. 875

[3] Matt Baillie Smith and Nina Laurie. 2011. International volunteering and development: Global citizenship and neoliberal professionalisation today. Transactions of the Institute of British Geographers 36, 4 (2011), 545-559. DOI :

http://dx.doi.org/10.1111/j.1475-5661.2011.00436.x

[4] Tom Bartindale, Guy Schofield, Clara Crivellaro, and Peter Wright. 2016. TryFilm: Situated Support for Interactive Media Productions. In Proceedings of the 19th ACM Conference on Computer-Supported Cooperative Work \& Social Computing (CSCW'16). ACM, New York, NY, USA, 1412-1422. DOI: http://dx.doi.org/10.1145/2818048.2819929

[5] Rosanna Bellini, Jay Rainey, Andrew Garbett, and Pamela Briggs. 2019. Vocalising Violence: Using Violent Mens' Voices for Service Delivery and Feedback. In Proceedings of the 9th International Conference on Communities \& Technologies Transforming Communities (C\&\#38;T'19). ACM, New York, NY, USA, 210-217. DOI : http://dx.doi.org/10.1145/3328320.3328405

[6] Alex Bowyer, Kyle Montague, Stuart Wheater, Ruth McGovern, Raghu Lingam, and Madeline Balaam. 2018. Understanding the Family Perspective on the Storage, Sharing and Handling of Family Civic Data. In Proceedings of the 2018 CHI Conference on Human Factors in Computing Systems - CHI'18, Vol. 18. ACM Press, New York, New York, USA, 1-13. DOI : http://dx.doi.org/10.1145/3173574.3173710

[7] Paul Brand and Anke Schwittay. 2006. The missing piece: Human-driven design and research in ICT and development. In 2006 International Conference on Information and Communication Technology and Development, ICTD2006. 2-10. DOI: http://dx.doi.org/10.1109/ICTD. 2006.301830

[8] Virginia Braun, Victoria Clarke, Nikki Hayfield, and Gareth Terry. 2018. Thematic analysis. Handbook of research methods in health social sciences (2018), 1-18. DOI : http://dx.doi.org/https: //doi.org/10.1007/978-981-10-2779-6_103-1

[9] Ernest W Brewer, Jacquelyn O DeJonge, and Vickie J Stout. 2001. Moving to online: Making the transition from traditional instruction and communication strategies. Corwin Press.
[10] Deana Brown and Rebecca E. Grinter. 2016. Designing for Transient Use: A Human-in-the-loop Translation Platform for Refugees. In Proceedings of the 2016 CHI Conference on Human Factors in Computing Systems (CHI '16). ACM, New York, NY, USA, 321-330. DOI : http://dx.doi.org/10.1145/2858036.2858230

[11] Jacqueline Butcher. 2003. A humanistic perspective on the volunteer-recipient relationship. In The values of volunteering. Springer, 111-125. DOI : http://dx.doi .org/10.1007/978-1-4615-0145-9_7

[12] Hanna Celina, Ahmed Kharrufa, Anne Preston, Rob Comber, and Patrick Olivier. 2016. SOLE meets MOOC. In Proceedings of the 2016 ACM Conference on Designing Interactive Systems - DIS '16. ACM Press, New York, New York, USA, 484-496. DOI : http://dx.doi.org/10.1145/2901790.2901848

[13] Nicola Dell and Neha Kumar. 2016. The Ins and Outs of HCI for Development. In Proceedings of the 2016 CHI Conference on Human Factors in Computing Systems (CHI'16). ACM, New York, NY, USA, 2220-2232. DOI : http://dx.doi .org/10.1145/2858036.2858081

[14] Nicola Dell, Vidya Vaidyanathan, Indrani Medhi, Edward Cutrell, and William Thies. 2012. "Yours is better!": Participant response bias in HCI. Proceedings of the 2012 ACM annual conference on Human Factors in Computing Systems - CHI '12 (2012), 1321-1330. DOI : http://dx.doi .org/10.1145/2207676.2208589

[15] Brian DeRenzi, Benjamin Birnbaum, Leah Findlater, Joachim Mangilima, Jonathan Payne, Tapan Parikh, Gaetano Borriello, and Neal Lesh. 2012. Improving community health worker performance through automated SMS. In Proceedings of the Fifth International Conference on Information and Communication Technologies and Development - ICTD '12. ACM Press, New York, New York, USA, 25. DOI : http://dx.doi.org/10.1145/2160673.2160677

[16] Ll Dodson, S Sterling, and Jk Bennett. 2013. Minding the gaps: cultural, technical and gender-based barriers to mobile use in oral-language Berber communities in Morocco. Proceedings of the Sixth International Conference on Information and Communication Technologies and Development 1 (2013), 79-88. DOI : http://dx.doi.org/10.1145/2516604.2516626

[17] Andy Dow, John Vines, Rob Comber, and Rob Wilson. 2016. ThoughtCloud: Exploring the role of feedback technologies in care organisations. In Proceedings of the 2016 CHI Conference on Human Factors in Computing Systems. ACM, 3625-3636. DOI :

http://dx.doi.org/10.1145/2858036.2858105

[18] M Edwards. 1997. Organizational learning in non-governmental organizations: What have we learned? Public Administration and Development: The International Journal of Management Research and Practice 17, 2 (1997), 235-250.

http://onlinelibrary.wiley.com/doi/10.1002/ 
[19] I S Eimhjellen. 2014. Internet Communication: Does It Strengthen Local Voluntary Organizations? Nonprofit and Voluntary Sector. Nonprofit and Voluntary Sector Quarterly 43, 5 (2014), 890-909. DOI : http://dx.doi.org/10.1177/0899764013487996

[20] Edim Azom Emmanuel. 2014. Speech User Interface for Low Literacy Users of Ict Services. European Journal of Computer Science and Information Technology 2, 1 (2014), 18-29.

[21] Marie-Hélène Ferrer, Jacob Hodges, and Nathalie Bonnardel. 2013. The MoLE project. In Proceedings of the 31st European Conference on Cognitive Ergonomics - ECCE '13. ACM Press, New York, New York, USA, 1. DOI : http://dx.doi.org/10.1145/2501907.2501963

[22] Henry Findley, Allison Reynolds, Bethany Davis, and William Belcher. 2013. Evolution of and current trends in training. Journal of Business and Economics 4, 8 (2013), 675-689.

http://www . aabri.com/N02013Manuscripts/N013056.pdf

[23] P.S. Foong, S. Zhao, F. Tan, and J.J. Williams. 2018. Harvesting caregiving knowledge: Design considerations for integrating volunteer input in dementia care. Conference on Human Factors in Computing Systems - Proceedings 2018-April (2018), 1-12. DOI : http://dx.doi.org/10.1145/3173574.3173653

[24] J Kevin Ford and Tyler Meyer. 2014. Advances in training technology: Meeting the workplace challenges of talent development, deep specialization and collaborative learning. In The psychology of workplace technology, Michael D. Coovert and Lori Foster Thompson (Eds.). 43-76.

[25] Kirrin Gill, Kim Brooks, Janna McDougall, Payal Patel, and Aslihan Kes. 2010. Bridging the gender divide. How technology can advance women economically. Technical Report. ICRW. https://www.icrw.org/publications/ bridging-the-gender-divide/

[26] Trina Gorman, Emma Rose, Judith Yaaqoubi, Andrew Bayor, and Beth Kolko. 2011. Adapting usability testing for oral, rural users. In Proceedings of the 2011 annual conference on Human factors in computing systems CHI'11. ACM Press, New York, New York, USA, 1437. DOI : http://dx.doi.org/10.1145/1978942.1979153

[27] Tobias Grundgeiger and Julian Hester. 2017. Beyond Knowledge Acquisition : Medical Device Training as a Cooperative Process. In Companion of the 2017 ACM Conference on Computer Supported Cooperative Work and Social Computing. 187-190. DOI:

http://dx.doi.org/10.1145/3022198. 3026315

[28] Nancy Hafkin, Nancy Taggart, and Others. 2001. Gender, information technology, and developing countries: An analytic study. Office of Women in Development, Bureau for Global Programs, Field Support and Research, United States Agency for International Development.
[29] Emily Harburg, Julie Hui, Michael Greenberg, and Elizabeth M Gerber. 2015. Understanding the Effects of Crowdfunding on Entrepreneurial Self-Efficacy. In Proceedings of the 18th ACM Conference on Computer Supported Cooperative Work \& Social Computing $C S C W$ '15. ACM Press, New York, New York, USA, 3-16. DOI : http://dx.doi.org/10.1145/2675133.2675142

[30] Jesse M. Heines, Jeff L. Popyack, Briana Morrison, Kate Lockwood, and Doug Baldwin. 2015. Panel on Flipped Classrooms. In Proceedings of the 46th ACM Technical Symposium on Computer Science Education (SIGCSE '15). ACM, New York, NY, USA, 174-175. DOI : http://dx.doi.org/10.1145/2676723.2677328

[31] Kenneth T Henson. 1993. Methods and strategies for teaching in secondary and middle schools. Longman Publishing Group, New York.

[32] Samuel Hickey and Giles Mohan. 2004. Participation-from tyranny to transformation?: Exploring new approaches to participation in development. Zed books, London, UK. DOI : http://dx.doi.org/10.1111/j.0012-155x.2005.00410.x

[33] Julie S Hui and Elizabeth M Gerber. 2017. Developing Makerspaces as Sites of Entrepreneurship. In Proceedings of the 2017 ACM Conference on Computer Supported Cooperative Work and Social Computing $C S C W$ '17. ACM Press, New York, New York, USA, 2023-2038. DOI :

http://dx.doi.org/10.1145/2998181.2998264

[34] Philip Ice, Reagan Curtis, Perry Phillips, and John Wells. 2007. Using Asynchronous Audio Feedback to Enhance Teaching Presence and Students' Sense of Community. Journal of Asynchronous Learning ... (2007), 3-25. DOI : http://dx.doi.org/10.24059/olj.v11i2.1724

[35] International Federation of Red Cross and Red Crescent Societies. 2014. Global Review on Volunteering. Technical Report. https://www .ifrc.org/what-we-do/ volunteers/global-review-on-volunteering/

[36] into23.com. 2019. Top 6 Asian Digital Trends in Digital 2019. https://into23. com/2019/05/29/

top-6-asian-trends-in-digital-2019/. (2019). [Online; accessed 09-August-2019].

[37] Miyeon Jung, Ju Hwan Kim, Juhwan Kim, and Hyo-Jeong So. 2016. Mark-On: Encouraging Student Questions in Class. In Proceedings of HCI Korea 2016. 79-86. DOI :

http://dx.doi.org/10.17210/hcik.2016.01.79

[38] Cecilia Katzeff and Vanessa Ware. 2006. Video storytelling as mediation of organizational learning. NordiCHI '06 Proceedings of the 4th Nordic conference on Human-computer interaction: changing roles October (2006), 311-320. DOI :

http://dx.doi.org/10.1145/1182475.1182508 
[39] Jane Kaye, Edgar A Whitley, Nadja Kanellopoulou, Sadie Creese, Kay J Hughes, and David Lund. 2011. Dynamic consent: a solution to a perennial problem?. In $B M C$, Vol. 343. BMJ Publishing Group.

[40] Konstantinos Kazakos, Siddhartha Asthana, Madeline Balaam, Mona Duggal, Amey Holden, Limalemla Jamir, Nanda Kishore Kannuri, Saurabh Kumar, Amarendar Reddy Manindla, Subhashini Arcot Manikam, G V S Murthy, Papreen Nahar, Peter Phillimore, Shreyaswi Sathyanath, Pushpendra Singh, Meenu Singh, Pete Wright, Deepika Yadav, and Patrick Olivier. 2016. A Real-Time IVR Platform for Community Radio. Proceedings of the $2016 \mathrm{CHI}$ Conference on Human Factors in Computing Systems (2016), 343-354. DOI:

http://dx.doi.org/10.1145/2858036.2858585

[41] Kemp, Simon. 2019. Digital trends 2019: Every single stat you need to know about the internet. https://bit.ly/35VfSuE. (2019). [Online; accessed 09-August-2019].

[42] Zahir Koradia, Piyush Aggarwal, Luthra Gaurav, and Aaditeshwar Seth. 2013. Gurgaon Idol : A singing competition over Community Radio and IVRS. Dev (2013). DOI :

http://dx.doi .org/10.1145/2442882.2442890

[43] M Kristensen, M Kyng, and L Palen. 2006. Participatory Design in Emergency Medical Service : Designing for Future Practice. Proceedings of the SIGCHI conference on Human factors in computing systems (2006), 161-170. DOI :

http://dx.doi.org/10.1145/1124772.1124798

[44] Kari Kuutti and Liam J Bannon. 2014. The turn to practice in HCI: towards a research agenda. In Proceedings of the SIGCHI Conference on Human Factors in Computing Systems. ACM, 3543-3552. DOI : http://dx.doi .org/10.1145/2556288.2557111

[45] Stephan Lukosch, Michael Klebl, and Tanja Buttler. 2011. Utilizing Verbally Told Stories for Informal Knowledge Management. Group Decision and Negotiation 20, 5 (2011), 615-642. DOI: http://dx.doi.org/10.1007/s10726-011-9237-7

[46] Meghana Marathe, Jacki O’Neill, Paromita Pain, and William Thies. 2015. Revisiting CGNet Swara and its impact in rural India. In Proceedings of the Seventh International Conference on Information and Communication Technologies and Development - ICTD '15. ACM Press, New York, New York, USA, 1-10. DOI : http://dx.doi.org/10.1145/2737856.2738026

[47] Wilbert McKeachie and Marilla Svinicki. 2010. McKeachie's teaching tips: Strategies, research, and theory for college and university teachers. Cengage Learning. 416 pages.
[48] Indrani Medhi, Somani Patnaik, Emma Brunskill, S.N. Nagasena Gautama, William Thies, and Kentaro Toyama. 2011. Designing mobile interfaces for novice and low-literacy users. ACM Transactions on Computer-Human Interaction 18, 1 (apr 2011), 1-28. DOI : http://dx.doi.org/10.1145/1959022.1959024

[49] Indrani Medhi-Thies, Pedro Ferreira, Nakull Gupta, Jacki O'Neill, and Edward Cutrell. 2015. KrishiPustak: A Social Networking System for Low-Literate Farmers. In Proceedings of the 18th ACM Conference on Computer Supported Cooperative Work \&\#38; Social Computing (CSCW'15). ACM, New York, NY, USA, 1670-1681. DOI:

http://dx.doi.org/10.1145/2675133.2675224

[50] Preeti Mudliar, Jonathan Donner, and William Thies. 2013. Swara : A Voice Forum for Citizen Journalism in Rural India. International Conference on Information and Communication Technologies and Development 9, 2 (2013), 65-79. DOI :

http://dx.doi.org/10.1145/2160673.2160695

[51] Michael J Muller. 2009. Participatory design: the third space in HCI. In Human-computer interaction. CRC press, 181-202. DOI : http://dx. doi .org/10.1201/9781420088892 . ch9

[52] Sharon Oviatt and Philip Cohen. 2000. Perceptual user interfaces: multimodal interfaces that process what comes naturally. Commun. ACM 43, 3 (mar 2000), 45-53. DOI : http://dx . doi .org/10.1145/330534.330538

[53] L Patel. 2010. ASTD State of the industry report 2010. Alexandria, VA: American Society for Training \& Development (2010).

[54] N Patel, D Chittamuru, A Jain, P Dave, and T S Parikh. 2010. Avaaj Otalo: a field study of an interactive voice forum for small farmers in rural India. In Proceedings of the 28th International Conference on Human Factors in Computing Systems - CHI'10.733-742. DOI : http://dx.doi.org/10.1145/1753326.1753434

[55] Gregory C. Petty and Ernest W. Brewer. 2011. Comparing Lecturing and Small Group Discussions. Encyclopedia of Information Communication Technologies and Adult Education Integration (2011), 396-414. DOI : http://dx.doi.org/10.4018/978-1-61692-906-0.ch024

[56] Gregory C Petty, Doo H Lim, and Jeff Zulauf. 2007. Training Transfer between CD-ROM Based Instruction and Traditional Classroom Instruction. Journal of Technology Studies 33, 1 (2007), 48-56.

[57] V Pipek, V Wulf, and A Johri. 2012. Bridging artifacts and actors: Expertise sharing in organizational ecosystems. Computer Supported Cooperative Work 21, 2-3 (2012), 261-282. DOI :

http://dx.doi .org/10.1007/s10606-011-9138-y 
[58] Jay Rainey, Kyle Montague, Pamela Briggs, Robert Anderson, Thomas Nappey, and Patrick Olivier. 2019. Gabber: Supporting Voice in Participatory Qualitative Practices. In Proceedings of the 2019 CHI Conference on Human Factors in Computing Systems (CHI '19). ACM, New York, NY, USA, Article 377, 377:1-377:12 pages. DOI : http://dx. doi .org/10.1145/3290605.3300607

[59] Eliza Marguerite Raymond and C Michael Hall. 2008. The Development of Cross-Cultural (Mis)Understanding Through Volunteer Tourism. Journal of Sustainable Tourism 16, 5 (dec 2008), 530. DOI : http://dx.doi.org/10.2167/jost796.0

[60] Aa Raza, Farhan Ul Haq, and Zain Tariq. 2013. Job opportunities through entertainment: virally spread speech-based services for low-literate users. Proceedings of the ... (2013), 2803-2812. DOI : http://dx.doi.org/10.1145/2470654.2481389

[61] Eduardo Salas and Janis A Cannon-bowers. 2001. The Science of Training: A Decade of Progress. Annual review of psychology (2001). DOI:

http://dx.doi.org/10.1146/annurev.psych.52.1.471

[62] Eduardo Salas, Scott I Tannenbaum, Kurt Kraiger, and Kimberly A Smith-jentsch. 2012. The Science of Training and Development in Organizations : What Matters in Practice. Psychological Science in the Public Interest 13, 2 (2012), 74-101. DOI:

http://dx. doi.org/10.2307/23484697

[63] T Schümmer and J M Haake. 2008. Supporting Social Practice Learning in NGOs. In Proceedings of the hypertext 2008 workshop on Collaboration and collective intelligence. 17-21. DOI:

http://dx.doi .org/10.1145/1379157.1379163

[64] Jahanzeb Sherwani, Nosheen Ali, Carolyn Penstein Rosé, and Roni Rosenfeld. 2009a. Orality-grounded HCID: Understanding the oral user. Information Technologies \& International Development 5, 4 (2009), pp-37.

[65] Jahanzeb Sherwani, Sooraj Palijo, Sarwat Mirza, Tanveer Ahmed, Nosheen Ali, and Roni Rosenfeld. 2009b. Speech vs. touch-tone: Telephony interfaces for information access by low literate users. 2009 International Conference on Information and Communication Technologies and Development, ICTD 2009 - Proceedings (2009), 447-457. DOI: http://dx.doi.org/10.1109/ictd.2009.5426682

[66] Cláudia Silva, Valentina Nisi, and Joseph D Straubhaar. 2017. Share Yourself First: Exploring Strategies for the Creation of Locative Content for and by Low-literacy Communities. Proceedings of the 8th International Conference on Communities and Technologies (2017), 236-245. DOI :

http://dx.doi.org/10.1145/3083671.3083698

[67] Brian Keith Simpkins. 2015. First Responder Training Transfer: Does Training delivery method matter? Ph.D. Dissertation. Eastern Kentucky University. http://encompass. eku. edu/etd/425/
[68] K Smith, H Hamerton, S Hunt, and RJ Sargisson. 2016. Local volunteers respond to the Rena oil spill in Maketū, New Zealand. In Kōtuitui: New Zealand Journal of Social Sciences Online. Vol. 11.1-10. DOI :

http://dx. doi .org/10.1080/1177083X.2015. 1009474

[69] Sharifa Sultana, François Guimbretière, Phoebe Sengers, and Nicola Dell. 2018. Design within a patriarchal society: Opportunities and challenges in designing for rural women in bangladesh. In Proceedings of the 2018 CHI Conference on Human Factors in Computing Systems. ACM, 536. DOI : http://dx.doi.org/10.1145/3173574.3174110

[70] Reem Talhouk, Sandra Mesmar, Anja Thieme, Madeline Balaam, Patrick Olivier, Chaza Akik, and Hala Ghattas. 2016. Syrian Refugees and Digital Health in Lebanon. In Proceedings of the 2016 CHI Conference on Human Factors in Computing Systems - CHI '16. ACM Press, New York, New York, USA, 331-342. DOI: http://dx.doi.org/10.1145/2858036.2858331

[71] Max Van Manen. 2016. Researching lived experience: Human science for an action sensitive pedagogy. Routledge, New York, USA. DOI : http://dx.doi.org/10.29173/pandp15124

[72] Delvin Varghese, Patrick Olivier, and Madeline Balaam. 2017. Citizen Tagger: Exploring social tagging of conversational audio. In IFIP Conference on Human-Computer Interaction. Mumbai, 116-125. DOI : http://dx.doi.org/10.1007/978-3-319-68059-0_7

[73] Aditya Vashistha, Edward Cutrell, Gaetano Borriello, and William Thies. 2015. Sangeet Swara. In Proceedings of the 33rd Annual ACM Conference on Human Factors in Computing Systems - CHI '15. ACM Press, New York, New York, USA, 417-426. DOI : http://dx.doi.org/10.1145/2702123.2702191

[74] John Vines, Rachel Clarke, and Peter Wright. 2013. Configuring participation: on how we involve people in design. Proceedings of the SIGCHI Conference on Human Factors in Computing Systems 20, 1 (2013), 429-438. DOI :

http://dx.doi .org/10.1016/S0142-694X(98)00026-X

[75] Frederick Weber, Kalika Bali, Roni Rosenfeld, and Kentaro Toyama. 2008. Unexplored directions in spoken language technology for development. In 2008 IEEE Spoken Language Technology Workshop, Vol. 81. 1-4. DOI : http://dx.doi .org/10.1109/SLT . 2008.4777825

[76] N Winters and K Toyama. 2009. From the Guest Editors: Human-Computer Interaction for Development: Mapping the Terrain. Information Technologies and International Development 5, 4 (2009), iII-viii.

[77] Worth, Jonathan. 2016. Connecting Classes \#CClasses. https://jonathanworth. org/connecting_classes/. (2016). [Online; accessed 09-August-2019].

[78] Barry J. Zimmerman. 2000. Self-Efficacy: An Essential Motive to Learn. Contemporary Educational Psychology 25, 1 (2000), 82-91. DOI : http://dx.doi.org/10.1006/ceps. 1999.1016 